\title{
Identifying the Effect of Inventive Problem Solving Approach (TRIZ) to Reducing Delays in Construction Projects; Case Study: Construction projects in NISOC ' Engineering and Construction Management
}

\author{
Mitra Zangeneh \\ Master of Industrial Management, Department of Industrial Management, Faculty of Management and Accounting, Tehran South \\ Branch, Islamic Azad University, Tehran, Iran \\ Email: Mitra.zangeneh80@gmail.com
}

*Ph.D.Golamreza Hashemzadeh Khoorasgani

Assistant Professor, Department of Industrial Management, Faculty of Management and Accounting, Tehran South Branch, Islamic Azad University, Tehran

Email: gh_hashemzadeh@azad.ac.ir

\section{Ph.D.Ghanbar Abbaspur Esfadan}

Assistant Professor, Department of Industrial Management, Faculty of Management and Accounting, Tehran South Branch, Islamic Azad University, Tehran Email: gh_abbaspur@azad.ac.ir

Doi:10.5901/mjss.2016.v7n4s1p257

\section{Abstract}

Considering the importance of delays in construction projects in NISOC ' engineering and construction management and the fact that completion of the project in due time to benefit from the plan in order to get back the investment is critical. Therefore, it is essential to revise the traditional methods of project management and achieve a new method in which the projects can get close to the real-time of scheduling. This study aimed to identify the effect of the Inventive Problem Solving theory (TRIZ) on reducing delays in construction projects in NISOC ' engineering and construction management. So, after setting the literature review and research hypothesis, the effect of this technique on reducing delays in the projects was examined by developing a coherent questionnaire. This is a descriptive-practical research, which uses Cochran formula in selecting the samples. The relevant questionnaires were analyzed using SPSS software and also descriptive and inferential statistics. The results showed that there is a significant positive correlation between inventive problem solving approach and the reduction of delays in construction projects. The effect of inventive problem solving approach on the variables of basic studies (designing), financing, supplying the efficient and specialized manpower, contractual ambiguities and lateral issues were also assessed. Eventually, using the research results, some strategies have presented to reduce the delays in construction projects in NISOC ' engineering and construction management as the population of this research.

Keywords: Creative Problem Solving (TRIZ), NISOC, Reducing Delays in the Project

\section{Introduction}

The term "delay" is a familiar word in the common literature of the project; in general, in industrial projects and in the oil industry, in particular. There have seen fewer projects that being completed without delay. Delay in completing projects is considered as one of the challenges of project-based organization, especially the oil industry, which has many ongoing projects. Also, the prevailing thinking about gaining experience and using it in the future projects to reduce the delay time have not been effective due to the diversity and fluidity of factors at different times. Therefore, investigating the causes of delay and solving problems of projects is a major issue, which should be addressed constantly over time and due to the changes in internal and external factors affecting the delay.

Investigating the effective factors and issues in slowing down the implementation of projects or the mismatch of the real time with project planning is critical and it will help project-based organizations to meet this dynamism and they can 
get the implementation of projects close to the real time of scheduling. NISOC${ }^{1}$, which produces the major part of the country's oil and gas, is the executor of many projects over a wide range of country's southern regions, and also uses massive resources and assets to further the industrial projects. Besides, losing the opportunities and assets; this company has lost the ability to increase the production due to the delay in implementation of projects, which this issue will lead to decrease in the future investments and is considered as an extra loss. Thus, it is essential to revise the traditional methods and achieve a new method in the planning and implementation of projects.

Delay in projects has some consequences that its negative impacts increases whatever goes ahead of its onset. Especially, delay in project often increases its completion cost as well causes hidden losses resulting from overdue exploitation of project (Reza Zade, 2005).

Currently, managers of NISOC are paying special attention to identifying the factors that have created the gap between planning and implementation and make possible to provide the appropriate solutions in order to achieve a reasonable time for taking the advantages of projects punctually. The country's economic structure and its strong dependence on the oil economy determine the fundamental role of the oil industry and its vital position in leading the current affairs, establishing economic infrastructures and developing country. So, the effective performance of this role depends on the implementation, completion and on time utilization of huge and complicate projects. It is important to identify factors that caused the delay and to achieve an attracting and controlling solution and reduce its negative impacts on NISOC and it has been addressed as an urgent need.

Inventive problem solving ${ }^{2}$ is a valuable technique that provides innovation mysteries and a way to overcome problems by its philosophy, methodology and set of tools.

The best idea is the one that needs the least time and cost for achieving to it and implementing. Inventive problem solving reduces the number of necessity experiments to solve the problem and provides the most effective solution for the intended problem (Narbut, 2005). It would be possible to access to the extraction and succinct of all problems' solution by using this method and with regard to the concept of inventive problem solving, we find that all issues have already been resolved somehow. Certainly, a lot of time would be wasted in the case of not using the inventive problem solving method.

\section{Objectives of the study}

Infrastructure projects in each country are as its infrastructures for development and economic progress. In this regard, the oil industry, which is seen as one of the pillars of the country's economic sectors, has a huge number of ongoing projects under the management of NISOC. The successful implementation of these projects plays a key role in the country's economic growth and remarkable asset has been spent for these continuous strategic planning's costs.

The major characteristics of this industry sector are extremely high amount of needed investments, the long interval between the onset of investments and capital recovery, conventional and unconventional risks associated with these investments and plurality of legal and executive contracts specific to this industry in oilfields. Identifying solutions that are effective in achieving predetermined objectives of these projects is very important for the company's management.

\subsection{The Main Objective}

Identifying the impact of inventive problem solving (TRIZ) in reducing the delay in construction projects of NISOC's engineering and construction management, improving the duration of project implementation and reducing the delay times in the industrial projects of this management is the main objective of this research.

\subsection{The Secondary Objectives}

Identifying the impact of inventive problem solving (TRIZ) on factors that cause delay in construction projects of NISOC'S engineering and construction management is the secondary objective of this research.

- The impact of inventive problem solving on the basic studies (designing)

- The impact of inventive problem solving on financing

- The impact of inventive problem solving on providing efficient and specialized manpower

- The impact of inventive problem solving on contractual ambiguities

\footnotetext{
${ }_{1}^{1}$ National Iranian South Oilfields Company

2 Teoriya Resheniya Izobreatatelskikh Zadatch
} 
- The impact of inventive problem solving on lateral issues

\subsection{The Applied Objective}

Familiarizing managers of the oil industry with the advised management and replacing scientific and systematic methods by traditional and old practices is the applied objective of this research.

\section{Research Questions}

Regarding the subject of this research, which is identifying the impact of applying the theory of inventive problem solving (TRIZ) to reduce the delay in construction projects, the present study has been conducted to meet the following questions:

\subsection{The Main Question of the Research}

What is the impact of theory of inventive problem solving (TRIZ) on reducing the delay in construction projects?

\subsection{The Secondary Questions of the Research}

- What is the impact of theory of inventive problem solving (TRIZ) on the basic studies (designing)?

- What is the impact of theory of inventive problem solving (TRIZ) on financing?

- What is the impact of theory of inventive problem solving (TRIZ) on providing efficient and specialized manpower?

- What is the impact of theory of inventive problem solving (TRIZ) on contractual ambiguities?

- What is the impact of theory of inventive problem solving (TRIZ) on the lateral issues of projects?

\section{Research hypotheses}

\subsection{The Main Hypothesis}

The theory of inventive problem solving has a significant impact on reducing the delay in construction projects.

\subsection{The Sub-hypotheses}

- The theory of inventive problem solving has a significant impact on the basic studies (designing).

- The theory of inventive problem solving has a significant impact on providing the financial resources.

- The theory of inventive problem solving has a significant impact on providing efficient and specialized manpower.

- The theory of inventive problem solving has a significant impact on contractual ambiguities.

- $\quad$ The theory of inventive problem solving has a significant impact on the lateral issues.

\section{Review of Literature}

\subsection{Theoretical Background}

\subsubsection{Inventive Problem Solving (TRIZ)}

The term "TRIZ" is derived from the first letters of Russian words "Teoriya Resheniya Lzobreatatelshikh Zadatch", its literal translation is "theory of the resolution of invention-related tasks" and TIPS 3 is the English acronym used for it.

Systematic innovation -theory of inventive problem solving- was one of the innovative methods for problem solving, which is developed by the Russian Genrich Altshuller in 1946 aimed at improving and accelerating inventors' works. Over the years, it has become a practical tool for invention as well solving the technical problems with various

\footnotetext{
${ }^{3}$ Theory of Inventive Problem Solving
} 
complexities.

First, research on inventive problem solution began with the idea that there are some general rules of innovation, which form the basis for creative innovation and lead to progress in technology. These rules could teach individuals to predict the innovation process and to take more steps on its path if they have been correctly identified, classified and encoded (Mann, 2002).

In 1946, Altshuller decided to create a new knowledge of the innovative theory. His findings on the theory of innovation were unordered and disorganized. Altshuller developed TRIZ by studying thousands of patent documents during two years (Terninko, 2001, Trans. Ja'fari).

While studying the patent documents, Altshuller found that a similar problem emerges in different innovations and various technologies over and over. This is especially evident when we are not limited to a certain field of technology. He also found that a similar solution has been used repeatedly and with long time intervals. So, these intervals will decrease when innovators are able to access to the foundational solutions. Therefore, the intervals between progresses decreases and the boundary between different technologies will be broken by using a more efficient innovative process.

Altshuller could achieve to TRIZ by studying two hundred thousand patent documents and choosing forty thousand creative ones of them. He could extract certain procedures for achieving any type of invention and initiative, as well (Terninko, 2001, Trans. Ja'fari).

The knowledge of developing problem-solving tools are used as one of the most powerful methods of solving the innovative problems in the world. Problem descriptions that are new and unfamiliar; yet, after solving the problems, there has not provided a known solution in any reference and sources. It is not possible to unravel such problems without using the creative thinking along with modern knowledge. Inventive problem solving is the only means of strengthening innovation and making dramatic improvements in designing.

\subsubsection{Project Delay}

Project: It is a set of unique and complex measures and operations that consists of logical and related activities. So that, the project implements under supervision of a certain executive organization and management for meeting the predetermined target/s within a pre-planned scheduling and budgeting framework (Yazdan Panah and Keshtiban, 2007).

A project is a temporary effort to develop a product or to deliver a service. More precisely, a project has the following characteristics: a start point and an end point, insight, measurable objectives and criteria, the logical sequence of actions and a final deliverability. Contrary to popular belief, projects run in all industries, including pharmaceutical, construction, and information and engineering systems (Ralph L, 2005).

Project management: Using the knowledge, skills, tools and techniques necessity for managing the implementation of these actions is in order to meet the needs and expectations of the custodians of implementing the project. Project management uses two powerful arms of planning and controlling the project in the implementation of this important issue (Yazdan Panah and Keshtiban, 2007).

Scheduling delays: Any failure to complete the activities at the planned time will result in the scheduling delays. It should always be aware that of the plan for each distinct activity can result from delay in the activity or been affected by the delay in its prerequisite activities. In other words, delay in each activity will have not necessarily been led to the delay in the project (Yazdan Panah and Keshtiban, 2007).

Project Delay: It is referred to as the variance between the predicted and the real-time of completing projects. This will be equal to the sum of the delays in the activities on the critical path (Yazdan Panah, 2007).

\subsubsection{The Costs Attributed to Project Delay}

These costs are divided into two main groups of qualitative and quantitative costs.

Quantitative costs can be simply estimated by using the tools in the science of engineering economy, etc., but, the qualitative costs are intangible and there is no cash payment for them. Some of the most important parts of these two delays are as follows:

Quantitative costs:

- The cost of lateness in exploitation or lost profits

- The cost attributed to raising the prices of consumable resources (materials, etc.)

- Increasing the cost of labor resources (manpower and equipment, etc.)

- The cost attributed to the interest of used capital 
Qualitative Costs:

- Detriment of losing competitive market during latency

- Detriment result from losing company's credit

- Project un-economization whether competitors cause to un-economization of the project by implementing similar projects or the nature of the project is time-dependent (most of the project related to the Internet and new technologies that rapidly change).

- The loss caused by reduction of government revenue and social welfare of people

- The losses and problems result from non-financial, social, cultural and political (projects related to the social welfare as construction of power plants, etc.) (Sabze Parvar, 2006).

\section{Empirical Background}

Studies that are conducted on the inventive problem solving as well project delays are as follows:

Arabi and A'zami Nejad (2009) in a paper entitled "Lack of Financing; The most Important factor of delay in construction projects in developing countries", have studied the causes of delay in construction projects. The paper notes that level of delay has been changed according to the atmosphere dominates the contracts, the presence or absence of credit, the experience of contractors, the experience of consultants, the issues related to the procurement, the existence of materials and environmental factors.

Fallah Tafti et al. (2011) in a paper entitled "Investigating the causes of delay in implementing the design and development projects (Case Study: Yazd Regional Electric Company)" have identified the causes of delay in projects of design and development in regional electronic companies. At first, they have tried to identify the nature of design and development projects; then, they have tried to identify the process of implementing projects and to determine the standard times of each stage of planning and their implementation. Afterward, using fieldwork method, possible causes of delay was identified. Ultimately, these factors were classified into nineteen major groups. They have attempted to rank them using $\mathrm{AHP}^{4}$ in order to provide practical solutions for the most important causes of delay.

Mansfield has identified sixteen important causes of time delays and increased costs in Nigeria. Setting payments and financial problems, poor contract management, lack of materials, incorrect estimates of time, cost and fluctuations in the price are the most important causes of delay (Reza Zade, 2005).

Motaleb and Kishk (2013) in a paper entitled "Investigating the Causes of Delays in Construction Projects in the UAE" have studied the growth rate of the delay in the delivery of projects. Then, they have proposed it as a great cash for construction companies that work in the UAE. This paper introduces factors such as contractors, consultants, project managers, costumers and financial resources as the important factors of delay in projects.

Tarhini et al. (2015) in a paper entitled "Designing Guidelines to Discover Causes of Delays in Construction Projects in Lebanon" have investigated the causes of delays in projects in Lebanon. The study noted that construction projects in the developed countries are prior to other projects since they are considered as a healthy investment in the unpredictable market. They also have introduced managing the project and its engineers, paying the provisional statement and financing, consultants, contractors and consumers as the factors of delays in projects.

Hanbing (2014) in a research entitled "Discovering the Contrasts between Decision-making Procedures in Construction Projects according to TRIZ Theory" has pointed to the specific application of TRIZ in construction projects. This study has provided some specified solutions for physical and technical contrasts in construction projects by using seventy-six standard solutions, separation principle, contradiction matrix and separately, the invention or innovation.

Li et al. (2014) in a paper entitled "TRIZ Leads to Mapping Patent (Case Study: Airplane Seat" have referred to the use of TRIZ in mechanical engineering. The paper notes that using TRIZ parameters and the contradiction matrix as a mediator is for introducing patent conflicts and it is a new contribution in the field of patent management. Also, this paper points that TRIZ is the effective factor in policy and strategy of patent that protect the decisions of inventors, R \& $D$ managers, lawyers and so on.

Padmanabhan (2013) in a paper entitled "A Study on the Reduction of Wind Power in Buildings using TRIZ Tools in Urban Areas" has investigated the use of TRIZ tools as a new method that causes the efficiency of the wind turbines in buildings. According to this study, different forms of buildings' upper covers have been used in various locations based on TRIZ or inventive problem solving.

Luing Swee et al. (2015) in a research entitled "Improvement of Power Efficiency by using TRIZ" have studied the reduction of residential electricity consumption by using TRIZ. Like contradiction matrix and the principles of innovation or

\footnotetext{
${ }^{4}$ Analytical Hierarchy Process Model
} 
invention, this research has used TRIZ tools as a solution to alleviate the problem.

Berdonosov et al. (2015) have investigated the role of TRIZ in a research entitled "TRIZ Evolution of Black Oil Coker Units". This study has ranked black oil Coker units by using TRIZ tools including, inventive principles, Su-field analysis, trends of systems development, etc.

Axavaan et al. (2011) have studied the use of innovative principles of inventive problem solving in accelerating the process of innovation in research and knowledge-based organizations. Results showed that researchers of the studied research center have subconsciously used the forty-fold principles of inventive problem solving in their innovative projects at a high level.

Seyed Javaadin et al. (2011) have identified the factors affecting the creativity of researchers in the field of human resources in the country's oil industry. Finally, they have pointed to seventeen factors affecting the creativity of researchers, which have categorized them in three groups of individual, organizational and professional.

In a study conducted by Basadur (2004), it was found that individuals, who were under training, were remarkably improved in generating ideas and creativity.

This study aimed at identifying the impact of applying inventive problem solving on factors affecting the delays in projects, which is as an advantage in the field of information management in eliminating or reducing the effect of these factors, avoiding waste of asset, and reducing the damages caused by delays in projects.

\section{The Research Conceptual Model}

The analytical model of research is presented as the following figure. In this figure, inventive problem solving (TRIZ) is the independent variable, and dependent variables include delays in construction projects, basic studies (designing), financing, efficient and specialized manpower, contractual ambiguities and lateral issues of construction projects.

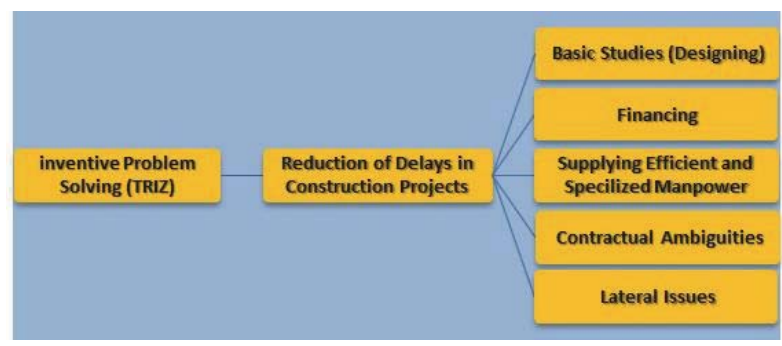

Figure 1. Research Conceptual Model

It should be noted that the dependent variables of this study were determined according to the researches that have been conducted in NISOC's engineering and construction management.

\section{Methodology}

This study is used a close-ended questionnaire. It is developed based on the Likert scale. Unlike the empirical research method, in which the researcher adjusts and manipulates the variable, this research is done by descriptive approach. In terms of its subject, this study is an applied research; since it seeks to find and offer solutions to improve the status quo. In terms of gathering data, this study is a survey research, that research hypotheses has been evaluated by using the questionnaire.

The sample size was obtained eighty-five from the population of this research, which was selected among onehundred of experts in NISOC's engineering and construction management, by using the Cochran formula as one of the simplest methods of determining the sample size for populations with specified and unspecified size.

Equation 1.

$$
n=\frac{\frac{z^{2} p q}{d^{2}}}{1+\frac{1}{N}\left(\frac{z^{2} p q}{d^{2}}-1\right)}
$$

Cronbach's alpha was used to the reliability of the research questionnaire, which this coefficient was calculated for 
each dependent variable and for each of the them, values of $0.903,0.711,0.789,0.792,0.761$ and 0.615 were obtained, which are aligned with the factors given in the above. Since the reliability of all factors is desirable, it can be inferred that research questionnaires have a high reliability.

For analyzing data obtained from the research questionnaire, Kolmogorov-Smirnov test is used for normality of its questions and one-sample t-test is used to examine the relationship between dependent and independent variables. Table 1. and 2. Show the summary of the tests results.

Table 1. The Result of Kolmogorov-Smirnov Test for Analyzing the Impact of Inventive Problem Solving Theory on the Factors Affecting Delays in Construction Projects

\begin{tabular}{|l|c|c|c|c|}
\hline Variable & Sig. & Error Level & Hypothesis Confirmation & Conclusion \\
\hline $\begin{array}{l}\text { Impact of inventive problem solving on reduction of delays in } \\
\text { construction projects }\end{array}$ & 0.896 & 0.05 & $\mathrm{H} 0$ & Normal \\
\hline Impact of inventive problem solving on basic studies (designing) & 0.409 & 0.05 & $\mathrm{H} 0$ & Normal \\
\hline Impact of inventive problem solving on financing & 0.251 & 0.05 & $\mathrm{H} 0$ & Normal \\
\hline $\begin{array}{l}\text { Impact of inventive problem solving on supplying efficient and } \\
\text { specialized manpower }\end{array}$ & 0.612 & 0.05 & $\mathrm{H} 0$ & Normal \\
\hline Impact of inventive problem solving on contractual ambiguities & 0.156 & 0.05 & $\mathrm{H} 0$ & Normal \\
\hline Impact of inventive problem solving on lateral issues & 0.051 & 0.05 & $\mathrm{H} 0$ & Normal \\
\hline
\end{tabular}

According to the test results in table 1., the observed distribution is equal to the theoretical distribution when the significance level is more than 0.05 and there is no difference between the two. It means that obtained distribution is closer to the normal distribution. But, the observed distribution differs from the theoretical distribution when the significance level is more than 0.05 , i.e. the mentioned distribution is not normal. Thus, the appropriate non-parametric tests should be used for further analysis.

The null hypothesis is accepted, since the significance level of all variables is more than error level of 0.05 , i.e. variable of impact of inventive problem solving on delays in construction projects, basic studies (designing), financing, supplying efficient and specialized manpower, contractual ambiguities and lateral issues of construction projects are normal.

Table 2. The Results of one-sample t-test is or Analyzing the Impact of Inventive Problem Solving Theory on the Factors Affecting Delays in Construction Projects

\begin{tabular}{|l|c|c|c|c|}
\hline Variable & Sig. & T & Hypothesis Confirmation & Conclusion \\
\hline $\begin{array}{l}\text { Impact of inventive problem solving on reduction of delays in } \\
\text { construction projects }\end{array}$ & 0.000 & 43.367 & $\mathrm{H} 1$ & $\mu>3$ \\
\hline Impact of inventive problem solving on basic studies (designing) & 0.000 & 35.815 & $\mathrm{H} 1$ & $\mu>3$ \\
\hline Impact of inventive problem solving on financing & 0.000 & 21.562 & $\mathrm{H} 1$ & $\mu>3$ \\
\hline $\begin{array}{l}\text { Impact of inventive problem solving on supplying efficient and } \\
\text { specialized manpower }\end{array}$ & 0.000 & 32.714 & $\mathrm{H} 1$ & $\mu>3$ \\
\hline Impact of inventive problem solving on contractual ambiguities & 0.000 & 30.856 & $\mathrm{H} 1$ & $\mu>3$ \\
\hline
\end{tabular}

According to the test results in table 1., the null hypothesis is concluded when significant level is more than error level of 0.05 ; and if the significant level is less than the error level of 0.05 , then $\mathrm{H} 1$ is accepted (The hypothesis is accepted when value of $\mathrm{T}$ is more than the value of 1.64).

The hypothesis of $\mathrm{H} 1$ is accepted, since the significant level of all variables equals to 0.000 and is more than error level of 0.05 (value of $T$ for all variables is more than the value of 1.64), i.e. variable of impact of inventive problem solving on delays in construction projects, basic studies (designing), financing, supplying efficient and specialized manpower, contractual ambiguities and lateral issues of construction projects has a significant effect. So, all hypotheses are accepted. 


\section{Findings}

\subsection{Findings of Kolmogorov-Smirnov Test and One-sample T-test}

Through using Kolmogorov-Smirnov test can conclude that impact of inventive problem solving for all variables, i.e. delays in construction projects, basic studies (designing), financing, supplying efficient and specialized manpower, contractual ambiguities and lateral issues of construction projects, is normal. Therefore, parametric and non-parametric test can be used to test them.

Then, the parametric one-sample t-test compares the mean of inventive problem solving (TRIZ) on the factors affecting the reduction of delays with the intermediate value of 3 for significant impact of inventive problem solving on the variables of reducing the delays in construction projects, basic studies (designing), financing, supplying efficient and specialized manpower, contractual ambiguities and lateral issues. The intended variable will have a significant impact on the population when the intended value is higher than 3; otherwise, the impact will not be significant.

\section{Conclusion}

According the one-sample t-test, there is a significant relationship for each hypothesis of research between dependent and independent variables. Therefore, administrators as well as engineering and construction management experts can use this technique to develop their management capability and resolve problems that cause delays in the construction projects.

So, it is recommended that the company's managers and experts to use TRIZ technique considering characteristics of project to resolve the shortcoming of basic studies (designing). This requires attracting and recruiting qualified and experienced personnel and considering appropriate educational strategies to empower their manpower. Also, they can minimize the delays in projects using this technique to finance the projects through correct and logical prediction and adopting appropriate strategies. Furthermore, they can resolve the ambiguities in contracts, including, selection of proper contractors by using the correct methods for selecting contractors, clear rules and regulations regarding the implementation of projects, and all aspects of the project implementation (accurate identification of opponents and environmental problems).

As inventive problem solving dating back more than sixty years in the world, has provided the necessity practical tools for this work. In case of other conditions, the rediscovery of the TRIZ tools and innovative solutions requires spending a time as much as the time which has been spent from the TRIZ onset till now; that it has no scientific justification and is not economical in terms of time and cost.

\subsection{Recommendations}

\subsection{Providing a Room for Thinking and Innovation:}

Since, the managers and experts have allocated most of their time to the routine affairs and engage in works and daily activities, there is no room for creative thinking and ideas. In order to resolve and eliminate this problem, it is recommended to the company to provide an opportunity for all staff to think and focus on finding ways to solve problems or improve their work's activities and processes during the day for a few hours (in a systematic form, individually or in a group). For this purpose, allocating a quiet and suitable place, without being disturbed, can be considered as one of the proper options in this regard; this place can be called "Thinking and Innovating Room".

\subsection{Considering the Staff Training}

As NISOC is considered as the greatest oil company among Iranian national oil companies, its department of education plays a strategic, influential and central role in this cycle, according to its objectives and facilities to supply a specialized and experienced manpower, as well.

Creativity can be acquired and it would be possible to promote individuals" creativity through training and familiarity with creativity tools and techniques.

It is required to teach its principles to the innovative people for further exploitation of inventive problem solving.

So, it can be concluded that if the organization wants to use the results of inventive problem solving to accelerate the innovation in its new services and product development, it should organize regular inventive problem solving training 
classes for staff in the NISOC's engineering and construction management and in particular intellectual manpower. In the same vein, management's greater trust to the intellectual manpower and supporting them will lead to increased confidence, risk-taking and success in the manpower.

Training programs should be realistic, flexible and compatible. In addition to the emergence of unpredictable problems, they should discuss about the problems of organization during exchanges the creative ideas.

Therefore, holding introductory courses for managers and experts with updated teachings of modern management in the field of developing creativity in an organization and familiarizing them with technique to enhance creativity and problem solving techniques such as inventive problem solving by inviting domestic and foreign professors and enjoying their valuable experiences can play an important role in promoting knowledge and awareness of staff, in this regard.

\subsection{Job Rotation in Innovative Staff}

It is required that management adopt a clear plan for job rotation in innovative staff, especially in brainy managers of the company. In this way, the experiences of these people are transferred to different units; also staffs acquire the necessary information for implementation of new projects while realizing the importance of creativity and innovation for managers.

\section{Reference}

Reza Zade, E. (2005). "Investigating the Causes of Delays in Dam Construction Projects and proposing some Suggestions to Reduce it", Quli Pour, MA Thesis, Tehran University, Tehran, 9.

Terninko, J.; Zusman, A.; Zlotin, B. (2001). "Inventive Problem Solving", (M. Ja'fari, Trans.), Fifth edition, Rasa cultural services Institute, Tehran.

Arabi, S and A'zami Nejad, B. (2009). "Lack of Financing the most Important Factors Affecting Delays in Construction Projects in Developing Countries", First conference on construction and management, Tehran, June.

Fallah Tafti, H and Ibrahimi Dahj, M and Rafi'e, A'. (2011). "Investigating the Causes of Delays in Implementing Design and Development Projects (Case Study: Yazd Regional Electric Company)", Twenty-sixth international conference on electricity.

Baqeri, M; Seyed Javaadin, R; Alishiri, M. (2011). "Identifying the Factors Affecting the Creativity in the field of Human Resources in Oil Industry", Journal of Scientific Research and Human Resources in the Oil Industry, V. 4, N. 14:9-30.

Sabze Parvar, M. (2006). "Project Control", Tehran: Terme Press, 215p.

Yazdan Panah, A.A; Keshtiban, Y. (2007). "A Guide for Project Management and its Concept", Managers Education Institute, 226p.

Axavaan, P; Ja'fari, M; Zarqami, H; Askari, N. (2011). "Investigating the Application of Inventive Problem Solving Principles to Accelerate the Process of Innovation in Knowledge-based and Research Organizations (Case Study: Intelligent Signal Processing Institute)", Journal of Towse'e Kar Afarini, V. 3, N. 11:187-206. 